\title{
Effect of Aspartame-Derived Phenylalanine on Neutral Amino Acid Uptake in Human Brain: A Positron Emission Tomography Study
}

\author{
Robert A. Koeppe, Barry L. Shulkin, Karen C. Rosenspire, Leslie A. Shaw, \\ $* \nmid \ddagger A$. Lorris Betz, Thomas Mangner, §Joy C. Price, and §\|\#Bernard W. Agranoff \\ Departments of Internal Medicine (Division of Nuclear Medicine), *Pediatrics, $\uparrow$ Neurology, $\ddagger$ Surgery, \\ $\S$ Psychiatry. and ||Biological Chemistry, and \#Mental Health Research Institute, \\ University of Michigan Medical School, Ann Arbor, Michigan, U.S.A.
}

\begin{abstract}
The possible effects of elevation of the plasma phenylalanine level secondary to the ingestion of aspartame on brain amino acid uptake in human subjects have been investigated by means of positron emission tomography (PET). $1-\left[{ }^{11} \mathrm{C}\right]$ Aminocyclohexanecarboxylate $\left(\left[{ }^{11} \mathrm{C}\right] \mathrm{ACHC}\right)$ is a poorly metabolized synthetic amino acid that crosses the blood-brain barrier by the same carrier that transports naturally occurring large neutral amino acids. Quantitative testretest PET studies were performed on 15 individuals. Seven received two identical baseline scans, whereas eight received a baseline scan followed by a scan performed $\sim 40-45 \mathrm{~min}$ following ingestion of an orange-flavored beverage containing $34 \mathrm{mg} / \mathrm{kg}$ of body weight of the low-calorie sweetener aspartame, a dose equivalent to the amount in $5 \mathrm{~L}$ of diet soft drink consumed all at once by the study subjects, weighing
\end{abstract}

an average of $76 \mathrm{~kg}$. The $40-45-\mathrm{min}$ interval was selected to maximize the detection of possible decreases in ACHC uptake resulting from increased competition for the carrier, because the plasma phenylalanine level is known to peak at this time. We observed an $11.5 \%$ decrease in the amino acid transport rate constant $K_{1}$ and a smaller decrease in the tissue distribution volume of $\mathrm{ACHC}(6 \%)$. Under conditions of normal dietary use, aspartame is thus unlikely to cause changes in brain amino acid uptake that are measurable by PET. Key Words: Amino acid transport-Phenylalanine-Aminocyclohexanecarboxylate-Aspartame-Positron emission tomography-Blood-brain barrier. Koeppe R. A. et al. Effect of aspartame-derived phenylalanine on neutral amino acid uptake in human brain: A positron emission tomography study. J. Neurochem. 56, 1526-1535 (1991).
Entry of many amino acids across the blood-brain barrier (BBB) into the brain occurs via a carrier-mediated process, the properties of which have been widely studied in animal models (Oldendorf, 1970; Oldendorf and Braun, 1976; Pardridge, 1977, 1983, 1986; Smith et al., 1987). This transport system, referred to as the large neutral amino acid (LNAA) carrier system, has been shown to transport the essential amino acids. The various substrates for the LNAA transport system all compete for the same binding site, and the carrier operates near saturation in normal biological conditions in the rat, with phenylalanine and leucine accounting for more than half of the carrier occupancy (Smith et al., 1987).
The dipeptide aspartame (L-aspartyl-L-phenylalanine methyl ester) is a widely used low-calorie sweetener. Aspartame is hydrolyzed in the human gut, and ingestion of large doses is followed by an increase in plasma levels of phenylalanine. Because of phenylalanine's high affinity for the LNAA carrier in animals $\left(K_{\mathrm{m}}=11 \mu \mathrm{mol} / \mathrm{L}\right.$ in rat cortex, as measured by Smith et al., 1987) and because the LNAA transport system normally operates near saturation, an increase in the concentration of phenylalanine in the plasma without a corresponding rise in the plasma concentrations of other essential amino acids might effectively reduce transport of these other amino acids across the BBB by competitive inhibition. Although the relative affin-
Received May 30, 1990; revised manuscript received September 26, 1990; accepted October 23, 1990.

Address correspondence and reprint requests to Dr. B. W. Agranoff at Mental Health Research Institute, University of Michigan, Neuroscience Laboratory Building, 1103 East Huron, Ann Arbor, MI 48104-1687, U.S.A.
Abbreviations used: ACHC, 1-aminocyclohexanecarboxylate; BBB blood-brain barrier; DV, distribution volume; LNAA, large neutral amino acid; PET, positron emission tomography. 
ities of amino acids for the LNAA carrier in the human BBB are not precisely known in vivo, the competitive effect of phenylalanine has been surmised to account for the developmental defect in phenylketonuria (Kaufman, 1977; Choi and Pardridge, 1986).

The effects of elevated plasma phenylalanine levels on uptake rates of other essential amino acids can be monitored by the use of trace amounts of a radiolabeled amino acid. Increases or decreases in the transfer rate of the radiotracer across the BBB reflect the combined effects of all other amino acids competing for the LNAA carrier. The effect of an individual amino acid on tracer uptake is determined by its $K_{\mathrm{m}}$ and its concentration in plasma (Pardridge, 1977).

To perform these experiments in humans, we developed a technique using the positron-emitting radiopharmaceutical probe ${ }^{11} \mathrm{C}$-labeled 1-aminocyclohexanecarboxylate $\left(\left[{ }^{11} \mathrm{C}\right] \mathrm{ACHC}\right)$ to measure $\mathrm{BBB}$ amino acid transport rates and brain distribution volume using positron emission tomography (PET) (Koeppe et al., 1990). We report here findings on the effects of aspartame-derived phenylalanine on amino acid transport $\left(K_{1}\right)$ and distribution volume (DV) as determined by test-retest PET studies performed on young normal human male control subjects. The significance of the observed effects and the limitations of the methods used to derive our findings are discussed.

\section{MATERIALS AND METHODS}

PET amino acid uptake studies were performed using $\left[{ }^{11} \mathrm{C}\right] \mathrm{ACHC}$, which was synthesized via a Bucherer-Strecker reaction of cyclohexanone with $\mathrm{H}^{11} \mathrm{CN}$ in the presence of ammonium carbonate and ammonium chloride according to the method of Hayes et al. (1978). After purification by ion-exchange chromatography, $>100 \mathrm{mCi}$ of product (corrected radiochemical yield, $\sim 50 \%$ ) was typically obtained 40-50 min following bombardment. [ $\left.{ }^{11} \mathrm{C}\right] \mathrm{ACHC}$ was formulated in normal saline solution and sterilized by filtration before administration. The injection volume of a $20 \mathrm{mCi}$ dose was 5-15 ml and contained a total ACHC mass of 2-5 $\mathrm{mg}(14-35 \mu \mathrm{mol})$. Radiochemical purity, as determined by radio-HPLC, was in all cases $>98 \%$. The absence of unreacted cyanide was confirmed by colorimetric assay before administration.

The research protocol was approved by an institutional review board (Human Subjects and Radioactive Drug Research Committees), and informed consent was obtained from all subjects before participation in the study. Subjects received brief physical and neurological examinations before the PET study and were assessed to be in good health. Two sequential [ $\left.{ }^{11} \mathrm{C}\right] \mathrm{ACHC}$ PET studies were performed within a 3-4-h interval in a single morning scanning session on each of 15 normal male volunteers between the ages of 19 and 33 years. Scans were acquired on a TCC PC4600A positron tomograph with in-plane resolution of 11-12 $\mathrm{mm}$ full-width at halfmaximum and axial resolution of $\sim 10 \mathrm{~mm}$ full-width at half-maximum. Scanner sensitivity is $\sim 20 \mathrm{kcps} / \mu \mathrm{Ci} / \mathrm{ml}$ in a $20-\mathrm{cm}$ phantom. The scanner provided five simultaneous tomographic slices separated by $11.5 \mathrm{~mm}$.

Subjects were separated into two groups: a "control" and an "aspartame" group. Subjects in both groups fasted over- night before the study. All subjects received $300 \mathrm{ml}$ of an unsweetened beverage (Wyler's orange-flavored drink mix; Thomas J. Lipton, Englewood Cliffs, NJ, U.S.A.) before the first PET scan ("placebo"). [ ${ }^{11}$ C]ACHC (10-20 mCi) in 5$15 \mathrm{ml}$ of normal saline solution was administered intravenously in a slow bolus injection (30-60 s). A dynamic sequence of 15 PET scans, covering a total of $60 \mathrm{~min}$, was initiated at the time of injection. Approximately $30 \mathrm{~min}$ to $1 \mathrm{~h}$ following the completion of the first PET study, control subjects received an additional $300 \mathrm{ml}$ of unsweetened drink, whereas the "aspartame" subjects received the drink containing, in addition, $34 \mathrm{mg}$ of aspartame $/ \mathrm{kg}$ of body weight. Approximately $40-45 \mathrm{~min}$ following ingestion of either "aspartame" or "placebo," subjects from both groups were injected with the second dose $(10-20 \mathrm{mCi})$ of $\left[{ }^{11} \mathrm{C}\right] \mathrm{ACHC}$ and underwent a repeat PET scan with an acquisition protocol identical to that for the first scan. The actual start time for the second scan ranged from 35 to $48 \mathrm{~min}$ following ingestion for six of the eight "aspartame" subjects, owing to variations in the time of delivery of $\left[{ }^{11} \mathrm{C}\right] \mathrm{ACHC}$. One of the other two subjects was inadvertently scanned only 17 min following aspartame ingestion, whereas the other subject was scanned $63 \mathrm{~min}$ after aspartame ingestion, owing to a delay in the chemical synthesis.

Arterial blood samples were withdrawn via a catheter placed in the radial artery. Samples were acquired as rapidly as possible for the first $2 \mathrm{~min}$ following $\left[{ }^{1} \mathrm{C}\right] \mathrm{ACHC}$ injection and then at progressively longer intervals, increasing to 10 $\mathrm{min}$ by the end of the study. Plasma samples, separated from red blood cells by centrifugation, were counted in a $\mathrm{Nal}$ scintillation well counter. Additional blood samples were drawn before each PET scan, at two times early in each scan, at the end of each scan, and at 3-4 $\mathrm{h}$ after the second PET scan, for determination of plasma amino acid concentrations. Plasma samples were placed on ice until the end of the study, frozen at $-70^{\circ} \mathrm{C}$, and shipped in dry ice to the laboratory of Dr. L. Stegink (University of Iowa) for analysis of amino acids by the methods of Lee (1974) and Mondino et al. (1975). Plasma concentrations were determined for phenylalanine, valine, isoleucine, leucine, methionine, histidine, tryptophan, and tyrosine.

Because ACHC is not metabolized in the brain (Aoyagi et al., 1988), a two-compartment (plasma and brain) two-rate parameter tracer kinetic model was applied to the dynamic PET data (Koeppe et al., 1990). The two-parameter fit provided estimates of the uptake rate constant, $K_{1}(\mathrm{ml} / \mathrm{g} / \mathrm{min})$, describing the carrier-facilitated transport from plasma across the $\mathrm{BBB}$, and the clearance rate constant, $k_{2}(1 / \mathrm{min})$, describing the rate of transport from brain back into blood. The ratio of these two parameters provides a measure of the radiotracer's tissue $\mathrm{DV}(\mathrm{ml} / \mathrm{g})$. A rapid pixel-by-pixel estimation procedure, using weighted integrals (Alpert et al., 1984), was used to provide functional images of the uptake and clearance rate constants and hence the DV for ACHC. The first $3 \mathrm{~min}$ of data were excluded from the estimation to minimize the effect from blood-borne radioactivity in the brain, which is large immediately following injection (Koeppe et al., 1990). Total calculation time for the estimation routine $(128 \times 128$ pixels, five planes, 15 frames of data) was $<5$ min on a VAX 750 minicomputer.

\section{RESULTS}

Table 1 reports plasma amino acid concentrations of the major LNAAs at 2-3 min after injection of 
TABLE 1. Plasma amino acid concentrations at time of PET scan: aspartame subjects

\begin{tabular}{|c|c|c|c|c|c|c|c|c|c|}
\hline Subject & Scan & Phe & Val & Ile & Leu & Met & His & Try & Tyr \\
\hline 1 & $\begin{array}{l}1 \\
2\end{array}$ & $\begin{array}{l}58.6 \\
127\end{array}$ & $\begin{array}{l}285 \\
281\end{array}$ & $\begin{array}{l}67.9 \\
55.6\end{array}$ & $\begin{array}{l}144 \\
13 !\end{array}$ & $\begin{array}{l}22.2 \\
22.7\end{array}$ & $\begin{array}{l}72.3 \\
75.0\end{array}$ & $\begin{array}{l}32.6 \\
28.5\end{array}$ & $\begin{array}{l}59.0 \\
76.6\end{array}$ \\
\hline 2 & $\begin{array}{l}1 \\
2\end{array}$ & $\begin{array}{l}41.3 \\
96.2\end{array}$ & $\begin{array}{l}176 \\
174\end{array}$ & $\begin{array}{l}47.3 \\
45.7\end{array}$ & $\begin{array}{l}107 \\
105\end{array}$ & $\begin{array}{l}17.1 \\
17.3\end{array}$ & $\begin{array}{l}72.3 \\
71.5\end{array}$ & $\begin{array}{r}9.6 \\
17.9\end{array}$ & $\begin{array}{l}55.0 \\
67.8\end{array}$ \\
\hline 3 & $\begin{array}{l}1 \\
2\end{array}$ & $\begin{array}{l}55.9 \\
158\end{array}$ & $\begin{array}{l}317 \\
294\end{array}$ & $\begin{array}{l}109 \\
110\end{array}$ & $\begin{array}{l}161 \\
161\end{array}$ & $\begin{array}{l}24.5 \\
24.3\end{array}$ & $\begin{array}{l}85.0 \\
87.1\end{array}$ & $\begin{array}{l}51.9 \\
56.4\end{array}$ & $\begin{array}{l}72.4 \\
145\end{array}$ \\
\hline 4 & $\begin{array}{l}1 \\
2\end{array}$ & $\begin{array}{l}45.5 \\
117\end{array}$ & $\begin{array}{l}236 \\
230\end{array}$ & $\begin{array}{l}67.6 \\
67.3\end{array}$ & $\begin{array}{l}129 \\
137\end{array}$ & $\begin{array}{l}19.6 \\
20.2\end{array}$ & $\begin{array}{l}108 \\
109\end{array}$ & $\begin{array}{l}57.3 \\
43.0\end{array}$ & $\begin{array}{l}39.6 \\
64.0\end{array}$ \\
\hline 5 & $\begin{array}{l}1 \\
2\end{array}$ & $\begin{array}{l}43.3 \\
138\end{array}$ & $\begin{array}{l}233 \\
222\end{array}$ & $\begin{array}{l}54.4 \\
50.4\end{array}$ & $\begin{array}{l}117 \\
110\end{array}$ & $\begin{array}{l}15.6 \\
14.9\end{array}$ & $\begin{array}{l}66.6 \\
70.7\end{array}$ & $\begin{array}{l}22.0 \\
26.0\end{array}$ & $\begin{array}{l}42.3 \\
79.5\end{array}$ \\
\hline 6 & $\begin{array}{l}1 \\
2\end{array}$ & $\begin{array}{l}66.1 \\
131\end{array}$ & $\begin{array}{l}175 \\
232\end{array}$ & $\begin{array}{l}59.1 \\
52.2\end{array}$ & $\begin{array}{l}130 \\
131\end{array}$ & $\begin{array}{l}30.3 \\
29.6\end{array}$ & $\begin{array}{l}97.4 \\
102\end{array}$ & $\begin{array}{l}52.2 \\
46.3\end{array}$ & $\begin{array}{l}78.7 \\
97.4\end{array}$ \\
\hline 7 & $\begin{array}{l}1 \\
2\end{array}$ & $\begin{array}{l}42.7 \\
59.7\end{array}$ & $\begin{array}{l}142 \\
143\end{array}$ & $\begin{array}{l}44.9 \\
42.0\end{array}$ & $\begin{array}{l}95.3 \\
94.5\end{array}$ & $\begin{array}{l}19.4 \\
18.3\end{array}$ & $\begin{array}{l}57.6 \\
62.7\end{array}$ & $\begin{array}{l}35.1 \\
29.7\end{array}$ & $\begin{array}{l}35.7 \\
38.5\end{array}$ \\
\hline 8 & $\begin{array}{l}1 \\
2\end{array}$ & $\begin{array}{l}45.7 \\
130\end{array}$ & $\begin{array}{l}133 \\
129\end{array}$ & $\begin{array}{l}47.6 \\
44.7\end{array}$ & $\begin{array}{l}92.8 \\
90.3\end{array}$ & $\begin{array}{l}19.7 \\
20.2\end{array}$ & $\begin{array}{l}65.7 \\
69.3\end{array}$ & $\begin{array}{l}40.9 \\
39.0\end{array}$ & $\begin{array}{l}48.5 \\
68.7\end{array}$ \\
\hline Mean \pm SD & $\begin{array}{l}1 \\
2\end{array}$ & $\begin{array}{c}49.9 \pm 9.1 \\
120 \pm 30\end{array}$ & $\begin{array}{l}212 \pm 67 \\
213 \pm 60\end{array}$ & $\begin{array}{l}62.6 \pm 20.9 \\
58.5 \pm 22.3\end{array}$ & $\begin{array}{l}122 \pm 24 \\
120 \pm 24\end{array}$ & $\begin{array}{l}21.1 \pm 4.6 \\
20.9 \pm 4.6\end{array}$ & $\begin{array}{l}78.1 \pm 17.3 \\
80.9 \pm 16.8\end{array}$ & $\begin{array}{l}37.7 \pm 16.4 \\
35.9 \pm 12.6\end{array}$ & $\begin{array}{l}53.9 \pm 15.5 \\
79.7 \pm 31.2\end{array}$ \\
\hline
\end{tabular}

Concentrations are given in $\mu \mathrm{mol} / \mathrm{L}$. Scan 1 is the baseline scan; scan 2 is $\sim 45 \mathrm{~min}$ following ingestion of $34 \mathrm{mg}$ of aspartame/kg of body weight.

$\left[{ }^{11} \mathrm{C}\right] \mathrm{ACHC}$ for both PET scans of each "aspartame" subject. Elevation in plasma phenylalanine levels is readily apparent following the ingestion of $34 \mathrm{mg}$ of aspartame $/ \mathrm{kg}$ of body weight. Transient increases from a mean baseline of $50 \mu \mathrm{mol} / \mathrm{L}$ to a mean peak of 120 $\mu \mathrm{mol} / \mathrm{L}$ are seen, with the peak levels occurring $\sim 40$ 45 min postingestion. Plasma concentrations of most other amino acids remained relatively unchanged with the exception of tyrosine, for which increases ranging from 30 to $>100 \%$ were measured. Plasma amino acid levels in the control subjects did not vary substantially during the course of the study. Figure 1 shows typical time courses of the ratio of phenylalanine to the sum of all seven of the other amino acids measured for both a control and an "aspartame" subject. To the extent that phenylalanine levels decline over the course of the second scan, some assumptions of the model are violated, the consequences of which are discussed below.

Functional images of the amino acid transport rate constant $\left(K_{1}\right)$ and DV for [ "C]ACHC in both a "control" and an "aspartame" subject are shown in Fig. 2A and $B$, respectively. One of the five image planes simultaneously acquired by the scanner is shown for a baseline-baseline study in Fig. 2A, and that for a baseline-aspartame study is given in Fig. 2B. The repeat baseline scans of the "control" subject have very similar values for transport and DV. Comparison of the two scans of the aspartame subject reveals a decline in the $\mathrm{ACHC}$ transport rate in the brain following aspartame ingestion. Of the eight "aspartame" subjects tested, this individual demonstrated one of the three highest re- sponses to aspartame, with a $25 \%$ decline in $K_{1}$ in brain ( $21 \%$ relative to scalp). Note that neither amino acid transport nor DV in scalp was substantially affected by plasma phenylalanine levels.

Table 2 shows mean global values of $K_{1}$ in brain and scalp for both PET scans on each subject. As seen in

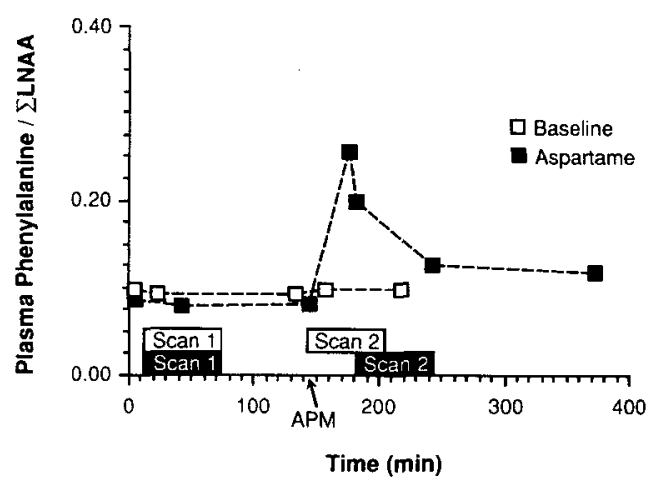

FIG. 1. Typical time courses of the ratio of phenylalanine concentration in plasma to the sum of all seven of the other LNAAs for both a subject receiving two baseline scans $(\square)$ and a subject receiving aspartame before the second scan ( $(0)$. The plasma phenylalanine concentration during the double baseline study was relatively constant, ranging from 46 to $52 \mu \mathrm{mol} / \mathrm{L}$, whereas the plasma phenylalanine concentration following aspartame administration increased from 56 to a peak of $211 \mu \mathrm{mol} / \mathrm{L}$. The scanning intervals for each subject are depicted along the time axis. APM, the time of aspartame administration for the "aspartame" subject, which for this subject was $35 \mathrm{~min}$ before the start of the second scan. 
FIG. 2. Amino acid transport rate (TR) and DV in test and retest scans in both double baseline and aspartame challenge conditions. A: Functional images of the amino acid transport rate constant $K_{1}$ (images on the left) and amino acid DV (images on the right) for $\left[{ }^{11} \mathrm{C}\right] \mathrm{ACHC}$ from a subject in the "control" group (subject 2; Table 2). Images are from one of the five levels simultaneously acquired by the scanner. $K_{1}$ and DV were estimated from a two-compartment two-parameter model, pixel-by-pixel, from the kinetic data sequences. The top pair of images is from the first baseline scan. The bottom pair of images is from the second baseline scan. Note the similar patterns and global values for both $K_{1}$ and DV in each scan. B: A similar set of images for a subject in the "aspartame" group (subject 8; Table 2). The top two images are again from a baseline scan. The bottom two images are from a retest scan following bolus ingestion of $34 \mathrm{mg}$ of aspartame $/ \mathrm{kg}$ of body weight. Note the global decline in brain values of ACHC TR seen in the retest scan (bottom left), whereas the TR values in scalp are relatively unchanged. This subject was one of the three highest responders to the aspartame challenge.
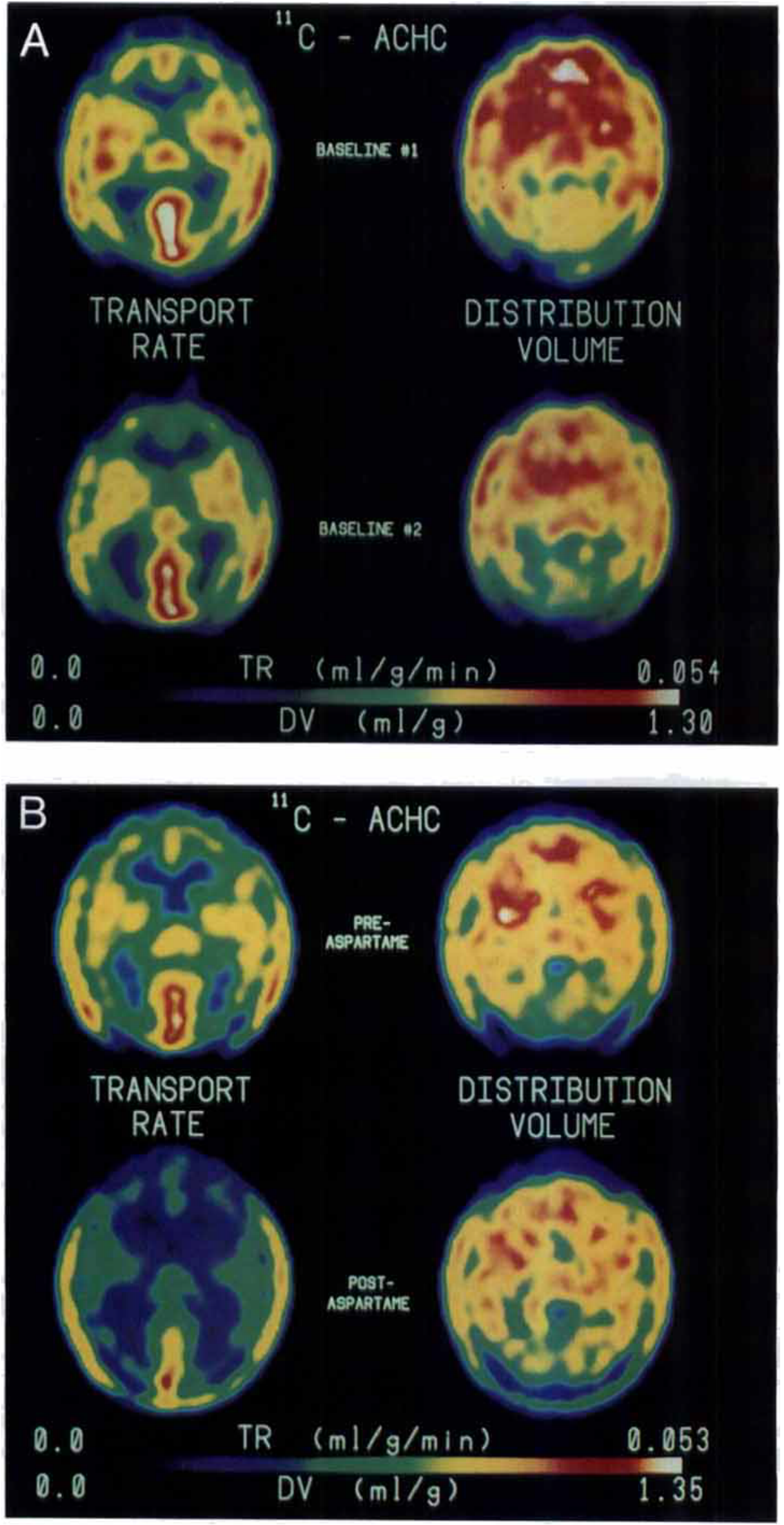
TABLE 2. Global values of amino acid transport rate constant, $\mathrm{K}_{1}(\mathrm{ml} / \mathrm{g} / \mathrm{min})$, in brain and scalp

\begin{tabular}{|c|c|c|c|c|c|c|}
\hline \multirow[b]{2}{*}{ Subject } & \multicolumn{3}{|c|}{ Brain } & \multicolumn{3}{|c|}{ Scalp } \\
\hline & Scan 1 & Scan 2 & $\%$ difference & Scan I & Scan 2 & $\begin{array}{l}\text { \% difference } \\
\text { brain/scalp }\end{array}$ \\
\hline \multicolumn{7}{|l|}{ Control subjects } \\
\hline 1 & 0.039 & 0.039 & 0.2 & 0.037 & 0.034 & 8.5 \\
\hline 2 & 0.037 & 0.036 & -2.7 & 0.034 & 0.033 & 0.8 \\
\hline 3 & 0.031 & 0.033 & 4.5 & 0.034 & 0.036 & -1.9 \\
\hline 4 & 0.034 & 0.034 & -1.2 & 0.037 & 0.032 & 12.3 \\
\hline 5 & 0.025 & 0.022 & -10.0 & 0.032 & 0.027 & 6.4 \\
\hline 6 & 0.035 & 0.030 & -15.1 & 0.038 & 0.029 & 4.1 \\
\hline 7 & 0.037 & 0.038 & 3.0 & 0.030 & 0.033 & -5.7 \\
\hline Mean \pm SD & $0.034 \pm 0.005^{a}$ & $0.033 \pm 0.006^{a}$ & $-3.0 \pm 7.1$ & $0.034 \pm 0.003^{b}$ & $0.032 \pm 0.003^{b}$ & $3.5 \pm 6.2$ \\
\hline \multicolumn{7}{|l|}{ Aspartame } \\
\hline 1 & 0.032 & 0.031 & -3.5 & 0.042 & 0.041 & -1.6 \\
\hline 2 & 0.031 & 0.026 & -14.0 & 0.027 & 0.028 & -17.1 \\
\hline 3 & 0.028 & 0.022 & -20.6 & 0.029 & 0.030 & -22.8 \\
\hline 4 & 0.026 & 0.021 & -17.4 & 0.025 & 0.027 & -22.7 \\
\hline 5 & 0.034 & 0.030 & -11.4 & 0.033 & 0.033 & -7.4 \\
\hline 6 & 0.027 & 0.029 & 7.3 & 0.039 & 0.041 & 1.8 \\
\hline 7 & 0.038 & 0.034 & -8.0 & 0.034 & 0.031 & -0.7 \\
\hline 8 & 0.034 & 0.026 & -25.5 & 0.036 & 0.033 & -20.6 \\
\hline Mean \pm SD & $0.031 \pm 0.004^{c}$ & $0.028 \pm 0.004^{c}$ & $-11.6 \pm 10.4$ & $0.034 \pm 0.006^{d}$ & $0.033 \pm 0.006^{d}$ & $-11.4 \pm 10.5$ \\
\hline
\end{tabular}

Scan 1 is a baseline scan in both groups of subjects; scan 2 is a baseline scan in the "control" group and is a challenge scan following ingestion of $34 \mathrm{mg}$ of aspartame $/ \mathrm{kg}$ of body weight in the "aspartame" group. Percent differences are given for brain and brain $/ \mathrm{scalp}$ as $100 \times(\mathrm{scan} 2$ - scan 1$) /$ scan 1.

${ }^{a}$ Paired $t=-1.09, p>0.05$ (not significant).

${ }^{b}$ Paired $t=-1.60, p>0.05$ (not significant).

${ }^{c}$ Paired $t=-3.19, p=0.02$.

${ }^{d}$ Paired $t=-0.24, p>0.05$ (not significant).

Fig. 2, the transport rate of $\left[{ }^{11} \mathrm{C}\right] \mathrm{ACHC}$ in scalp appears to be as high as in brain, a finding indicating a high extraction fraction, because PET measures of blood flow in scalp are quite low compared with brain. This observation and the lack of influence of plasma amino acid levels on the scalp transport rate suggest that simple diffusion or very-low-affinity uptake is the dominant mode of uptake in scalp, rather than carrier-mediated transport. Thus, the scalp may serve to provide normalized or relative values of transport. Global means of $K_{1}$ in brain ranged from 0.022 to $0.039 \mathrm{ml} / \mathrm{g} / \mathrm{min}$ in "control" subjects. If it is assumed that the global mean cerebral blood flow in normal subjects ranges from 0.4 to $0.6 \mathrm{ml} / \mathrm{g} / \mathrm{min}$, this indicates that the singlepass extraction fraction is $<10 \%$, because extraction equals $K_{1}$ divided by cerebral blood flow. Also shown is the percent change in mean $K_{1}$ from the second PET scan relative to the first for each subject. Changes in both the absolute value of whole brain $K_{1}$ and in $K_{1}$ normalized to scalp, i.e., the change in the brain-toscalp ratio of $K_{1}$, are given. Absolute changes in $K_{1}$ between the test-retest scans on "control" subjects decreased by an average of $3 \%$ (range, -15 to $+5 \%$ ), whereas changes between scans on "aspartame" subjects decreased by an average of $12 \%$ (range, -25 to $+7 \%$ ). Transport changes in brain relative to scalp increased by an average of $3 \%$ between scans in the "control" group (range, -6 to $+12 \%$ ), whereas relative changes in the "aspartame" group decreased by an average of $11 \%$ (range, -22 to $+2 \%$ ). These changes were significant at $p<0.05$ (paired $t$ test) in the "aspartame" group for both absolute and normalized data but were not significant in the "control" group.

Table 3 shows mean and SD values for regional values of transport rate for the test-retest studies of each group. Decreases in the range of $10 \%$ were seen in all brain structures examined following aspartame ingestion with minimal regional variation. Scalp, as anticipated, showed no response following aspartame ingestion. Cerebellum exhibited a lesser and more variable decline than other brain regions, which did not reach statistical significance. In contrast, the "control" group exhibited no significant differences between first and second scans in any of the regions examined. Table 4 presents regional brain values normalized to scalp, with findings similar to those obtained from the absolute data reported in Table 3. Also reported in the last two columns of Table 4 are between-group comparisons for both scan 1 (baseline vs. baseline) and scan 2 (baseline vs. aspartame challenge), which further validate the effect of aspartame on amino acid uptake.

Table 5 reports mean global values for ACHC DV and clearance rate constant for the two scans of each subject. Both DV and $k_{2}$ were decreased in the "aspartame" group but by lesser amounts than observed in $K_{1}$ (see Table 2) and with statistical significance only 
TABLE 3. Regional transport rate constant values for $\left[{ }^{11} \mathrm{CJACHC}\right.$

\begin{tabular}{|c|c|c|c|c|c|c|}
\hline \multirow[b]{2}{*}{ Region } & \multicolumn{3}{|c|}{$\begin{array}{l}\text { Aspartame subjects } \\
\qquad(\mathrm{n}=8)\end{array}$} & \multicolumn{3}{|c|}{$\begin{array}{l}\text { Control subjects } \\
\quad(n=7)\end{array}$} \\
\hline & Baseline & Aspartame & $\begin{array}{l}\text { Paired } \\
t \text { value }\end{array}$ & Baseline 1 & Baseline 2 & $\begin{array}{l}\text { Paired } \\
t \text { value }\end{array}$ \\
\hline Whole brain & $0.031 \pm 0.004$ & $0.028 \pm 0.004$ & $-3.19^{a}$ & $0.034 \pm 0.005$ & $0.033 \pm 0.006$ & -1.09 \\
\hline Scalp & $0.033 \pm 0.006$ & $0.033 \pm 0.006$ & -0.24 & $0.034 \pm 0.003$ & $0.032 \pm 0.003$ & -1.60 \\
\hline Cerebellum & $0.043 \pm 0.007$ & $0.039 \pm 0.009$ & -1.59 & $0.044 \pm 0.006$ & $0.043 \pm 0.007$ & -0.72 \\
\hline Temporal & $0.033 \pm 0.005$ & $0.029 \pm 0.005$ & $-4.23^{b}$ & $0.037 \pm 0.005$ & $0.036 \pm 0.005$ & -1.81 \\
\hline Frontal & $0.032 \pm 0.005$ & $0.028 \pm 0.005$ & $-3.69^{b}$ & $0.036 \pm 0.006$ & $0.036 \pm 0.008$ & 0.29 \\
\hline Parietal & $0.033 \pm 0.006$ & $0.029 \pm 0.005$ & -2.27 & $0.036 \pm 0.006$ & $0.036 \pm 0.007$ & -0.34 \\
\hline Caudate & $0.031 \pm 0.003$ & $0.028 \pm 0.004$ & $-3.67^{b}$ & $0.034 \pm 0.006$ & $0.033 \pm 0.006$ & -2.04 \\
\hline Putamen & $0.035 \pm 0.005$ & $0.031 \pm 0.006$ & $-2.58^{a}$ & $0.039 \pm 0.006$ & $0.038 \pm 0.008$ & -1.02 \\
\hline Thalamus & $0.037 \pm 0.004$ & $0.030 \pm 0.007$ & $-5.98^{b}$ & $0.037 \pm 0.006$ & $0.037 \pm 0.008$ & 0.01 \\
\hline
\end{tabular}

Data are mean \pm SD values. $K_{1}$ values are given in $\mathrm{ml} / \mathrm{g} / \mathrm{min}$.

${ }^{a} p<0.05$ by two-tailed paired Student's $t$ test.

${ }^{b} p<0.01$ by two-tailed paired Student's $t$ test.

in DV. No significant differences between scans were observed in either DV or $k_{2}$ for the "control" group.

\section{DISCUSSION}

PET makes possible the application of biochemical methods to the study of regional brain function heretofore restricted to experiments that require direct intervention and processing of the brains of experimental animals (Frey, 1989). The noninvasive property of PET is advantageous for the obvious reason that many physiopathologic conditions are known to occur only in humans and would not otherwise be amenable to direct biochemical study. In addition, noninvasive approaches make it possible for the same individual to serve as both control and experimental subject in a test-retest experimental design. The test-retest design thus has the potential additional advantage that variation in experimental parameters measured repetitively in the same subject may be less than it is between subjects.
In the present study the test-retest design is used to investigate the possibility that ingestion of a large amount of aspartame over a brief interval measurably affects brain uptake of amino acids that compete with phenylalanine for BBB transport via the LNAA carrier. Animal studies have demonstrated this competitive effect, i.e., an increase in the amount of one plasma amino acid causes decreases in BBB uptake of the other amino acids. Consequently, such an amino acid imbalance might affect protein or neurotransmitter synthesis in the brain. This mechanism has been proposed as the primary cause of the adverse developments seen in phenylketonuria. It has been suggested that a similar problem might arise from aspartame ingestion, because this substance can also produce transient increases in plasma phenylalanine levels (Choi and Pardridge, 1986). In vitro methods, using isolated human brain capillaries, have indicated that both high- $\left(K_{\mathrm{m}}=0.26\right.$ $\mu \mathrm{mol} / \mathrm{L})$ and low- $\left(K_{\mathrm{m}}=22.3 \mu \mathrm{mol} / \mathrm{L}\right)$ affinity carrier systems exist for phenylalanine (Choi and Pardridge, 1986), and it was suggested that the low-affinity carrier

TABLE 4. Regional transport rate constant values normalized to scalp

\begin{tabular}{|c|c|c|c|c|c|c|c|c|}
\hline \multirow[b]{2}{*}{ Region } & \multicolumn{3}{|c|}{$\begin{array}{l}\text { Aspartame subjects } \\
\qquad(\mathrm{n}=8)\end{array}$} & \multicolumn{3}{|c|}{$\begin{array}{l}\text { Control subjects } \\
\quad(\mathrm{n}=7)\end{array}$} & \multicolumn{2}{|c|}{$\begin{array}{l}\text { Aspartame vs. } \\
\text { control }\end{array}$} \\
\hline & $\begin{array}{c}\text { Scan } 1 \\
\text { baseline }\end{array}$ & $\begin{array}{c}\text { Scan } 2 \\
\text { aspartame }\end{array}$ & $\begin{array}{l}\text { Paired } \\
t \text { value }\end{array}$ & $\begin{array}{c}\text { Scan 1 } \\
\text { baseline } 1\end{array}$ & $\begin{array}{c}\text { Scan } 2 \\
\text { baseline } 2\end{array}$ & $\begin{array}{l}\text { Paired } \\
t \text { value }\end{array}$ & $\begin{array}{l}\text { Scan } 1 \\
t \text { value }\end{array}$ & $\begin{array}{l}\text { Scan } 2 \\
t \text { value }\end{array}$ \\
\hline Whole brain & $0.96 \pm 0.16$ & $0.84 \pm 0.13$ & $-2.98^{a}$ & $0.99 \pm 0.14$ & $1.03 \pm 0.12$ & 1.55 & 0.43 & $2.79^{a}$ \\
\hline Cerebellum & $1.30 \pm 0.12$ & $1.19 \pm 0.22$ & -1.34 & $1.29 \pm 0.22$ & $1.33 \pm 0.15$ & 0.86 & 0.13 & 1.44 \\
\hline Temporal & $1.01 \pm 0.17$ & $0.89 \pm 0.17$ & $-3.84^{b}$ & $1.09 \pm 0.16$ & $1.11 \pm 0.11$ & 0.68 & 0.88 & $2.87^{a}$ \\
\hline Frontal & $0.99 \pm 0.15$ & $0.86 \pm 0.16$ & $-3.53^{b}$ & $1.05 \pm 0.17$ & $1.13 \pm 0.20$ & 1.69 & 0.66 & $2.94^{a}$ \\
\hline Parietal & $1.01 \pm 0.16$ & $0.88 \pm 0.13$ & $-2.54^{a}$ & $1.05 \pm 0.17$ & $1.11 \pm 0.17$ & 1.85 & 0.42 & $2.97^{a}$ \\
\hline Caudate & $0.97 \pm 0.16$ & $0.85 \pm 0.18$ & $-4.10^{b}$ & $1.00 \pm 0.19$ & $1.03 \pm 0.15$ & 0.87 & 0.34 & 2.00 \\
\hline Putamen & $1.09 \pm 0.17$ & $0.95 \pm 0.20$ & $-2.42^{a}$ & $1.13 \pm 0.19$ & $1.17 \pm 0.19$ & 0.99 & 0.48 & $2.28^{a}$ \\
\hline Thalamus & $1.14 \pm 0.18$ & $0.91 \pm 0.24$ & $-3.72^{b}$ & $1.08 \pm 0.19$ & $1.14 \pm 0.18$ & 1.66 & 0.62 & 2.14 \\
\hline
\end{tabular}

Data are mean and SD values of normalized $K_{1}$. Paired $t$ tests are within-group comparisons; unpaired $t$ tests are between-group comparisons.

${ }^{a} p<0.05$ by two-tailed Student's $t$ test.

${ }^{b} p<0.01$ by two-tailed Student's $t$ test. 
TABLE 5. Global values of amino acid $D V$ and clearance rate constant, $\mathrm{k}_{2}$, in brain

\begin{tabular}{|c|c|c|c|c|}
\hline \multirow[b]{2}{*}{ Subject } & \multicolumn{2}{|c|}{$\mathrm{DV}(\mathrm{ml} / \mathrm{g})$} & \multicolumn{2}{|c|}{$k_{2}(1 / \mathrm{min})$} \\
\hline & Scan 1 & Scan 2 & Scan 1 & Scan 2 \\
\hline \multicolumn{5}{|l|}{ Control } \\
\hline 1 & 0.86 & 0.87 & 0.045 & 0.045 \\
\hline 2 & 1.02 & 0.95 & 0.036 & 0.038 \\
\hline 3 & 0.93 & 0.97 & 0.034 & 0.034 \\
\hline 4 & 1.07 & 1.05 & 0.032 & 0.032 \\
\hline 5 & 0.71 & 0.71 & 0.035 & 0.032 \\
\hline 6 & 0.88 & 0.88 & 0.040 & 0.034 \\
\hline 7 & 0.98 & 1.21 & 0.038 & 0.031 \\
\hline Mean $\pm S D$ & $0.92 \pm 0.12^{a}$ & $0.95 \pm 0.16^{a}$ & $0.037 \pm 0.005^{b}$ & $0.035 \pm 0.005^{b}$ \\
\hline \multicolumn{5}{|l|}{ Aspartame } \\
\hline 1 & 0.68 & 0.72 & 0.046 & 0.043 \\
\hline 2 & 1.04 & 0.92 & 0.030 & 0.029 \\
\hline 3 & 0.89 & 0.78 & 0.031 & 0.029 \\
\hline 4 & 0.71 & 0.71 & 0.036 & 0.030 \\
\hline 5 & 1.02 & 0.88 & 0.033 & 0.034 \\
\hline 6 & 0.90 & 0.98 & 0.030 & 0.030 \\
\hline 7 & 1.06 & 0.82 & 0.035 & 0.042 \\
\hline 8 & 1.11 & 1.06 & 0.031 & 0.024 \\
\hline Mean \pm SD & $0.93 \pm 0.16^{c}$ & $0.86 \pm 0.12^{c}$ & $0.034 \pm 0.006^{d}$ & $0.033 \pm 0.007^{d}$ \\
\hline
\end{tabular}

Scan 1 is a baseline scan in both groups of subjects; scan 2 is a baseline scan in the "control" group and is a challenge scan following ingestion of $34 \mathrm{mg}$ of aspartame $/ \mathrm{kg}$ of body weight in the "aspartame" group.

${ }^{a}$ Paired $t=0.70, p>0.05$ (not significant).

${ }^{b}$ Paired $t=-1.67, p>0.05$ (not significant).

${ }^{c}$ Paired $t=-3.0, p=0.03$.

${ }^{d}$ Paired $t=-0.36, p>0.05$ (not significant).

is primarily responsible for mediating amino acid transport from blood to brain. More recent work (Hargreaves and Pardridge, 1988), also using isolated human brain capillaries, reported $K_{\mathrm{m}}$ values for the highaffinity carrier of seven other neutral amino acids in addition to phenylalanine, with values ranging from $0.30 \mu \mathrm{mol} / \mathrm{L}$ for phenylalanine to $8.8 \mu \mathrm{mol} / \mathrm{L}$ for valine, and favors the possibility that the high-affinity carrier mediates amino acid entry into the brain.

Because the affinities of amino acids for the LNAA carrier in the human have not been precisely determined in vivo, the magnitude of any effect of aspartame on amino acid uptake across the human BBB cannot be precisely estimated without experimental investigation, such as is reported here. The dose selected for this study, $34 \mathrm{mg}$ of aspartame $/ \mathrm{kg}$ of body weight, was the 99th percentile of estimated consumption before the approval of aspartame by the Food and Drug Administration in 1981. This dose is equivalent to the amount of aspartame in $\sim 5 \mathrm{~L}$ of diet soft drink beverage sweetened with aspartame consumed at a single sitting by the study subjects, whose mean weight was $76.3 \mathrm{~kg}$. This assumes that $1 \mathrm{~L}$ of sweetened beverage contains $500 \mathrm{mg}$ of aspartame (Homler, 1984). This level is well above the current $90 \mathrm{th}$ percentile of actual aspartame consumption for all ages $(2-4 \mathrm{mg} / \mathrm{kg} /$ day, depending on the age) over the course of a day by a typical user of the sweetener (Butchko and Kotsonis, 1989). It has been estimated that if aspartame replaced all dietary sucrose, typical consumption would be $\sim 8.3$ $\mathrm{mg} / \mathrm{kg}$ of body weight/day (Food and Drug Administration, 1981). The $34 \mathrm{mg} / \mathrm{kg}$ dose also approaches the solubility limit of aspartame in a reasonable volume of a cold aqueous drink to be consumed at once.

$\left[{ }^{11} \mathrm{C}\right] \mathrm{ACHC}$, a nonmetabolizable synthetic amino acid with an affinity for the LNAA carrier in rats similar to that of several of the essential amino acids, was selected as a suitable agent to measure rates of BBB transport. Washburn et al. (1981) proposed that $\left[{ }^{11} \mathrm{C}\right] \mathrm{ACHC}$ would have an affinity for transport similar to those of many of the natural amino acids transported by the LNAA carrier. Work by Aoyagi et al. (1988) has since demonstrated that the $V_{\max }\left(9 \times 10^{4} \mu \mathrm{mol} / \mathrm{s} / \mathrm{g}\right)$ and $K_{\mathrm{m}}(53 \mu \mathrm{mol} / \mathrm{L})$ for transport of $\mathrm{ACHC}$ at the rat BBB are indeed close to those of tyrosine, methionine, and isoleucine. An advantage of the use of a nonmetabolized amino acid analog such as ACHC for measuring the transport process compared with the use of a natural amino acid is that the interpretation of its kinetics is relatively straightforward, because there is no need to compute breakdown of tracer or incorporation into proteins that results in multiple chemical forms of the radiolabel. Also, because there are no asymmetric carbon atoms in $\left[{ }^{11} \mathrm{C}\right] \mathrm{ACHC}$, separation of stereoisomers is unnecessary. Koeppe et al. (1990) have recently shown $\left[{ }^{11} \mathrm{C}\right] \mathrm{ACHC}$ to be a useful agent for the in vivo measurement of $\mathrm{BBB}$ amino acid transport rate and brain DV using dynamic PET.

The transport rate of $\left[{ }^{11} \mathrm{C}\right] \mathrm{ACHC}$, like that of a given natural amino acid, is determined by the product of 
its transport rate constant, $K_{1}$, and its plasma concentration. Thus, because the concentration of phenylalanine increases selectively following ingestion of aspartame, the change in transport rate of another essential amino acid will be directly proportional to the change in its $K_{1}$. The $K_{1}$ for a particular amino acid is primarily determined by two factors: the amino acid's affinity for the LNAA carrier and the total level of competition for the carrier from all other amino acids. Because an amino acid's affinity for the carrier is a fixed value, the magnitude of the decrease in the transport rate of $\left[{ }^{11} \mathrm{C}\right] \mathrm{ACHC}$, or any other LNAA, is related to the total level of competition. Thus, as long as the plasma level of any particular amino acid does not change, the decrease in ACHC uptake provides a measure of the decrease in uptake of that amino acid.

- Because aspartame ingestion selectively raises plasma phenylalanine (and, to a lesser extent, tyrosine) levels, decreases in uptake of $\left[{ }^{11} \mathrm{C}\right] \mathrm{ACHC}$ can be ascribed to the increase in plasma phenylalanine level. It should be borne in mind that other dietary effects on plasma amino acid levels, such as would follow protein (Fernstrom et al., 1979) or carbohydrate (Martin-Du Pan et al., 1982; Hurwitz, 1989) ingestion, could produce similar or greater changes in ACHC uptake. The effects on another amino acid under these conditions would depend on the change in its plasma concentration relative to the change of the other LNAA plasma concentrations. In such situations, decreases in $\mathrm{ACHC}$ uptake would be predictive only of those amino acids whose plasma levels had not been altered substantially.

The variability of plasma phenylalanine responses to ingestion of aspartame can be seen in Table 2. Results are presented for both absolute values (in $\mathrm{ml} / \mathrm{g}$ / $\mathrm{min}$ ) and for values normalized to scalp. Even though the absolute transport rates are of primary interest in this study, it is generally accepted that the greatest single source of variability in PET measurements is of a global nature (Fox et al., 1984; Mazziotta et al., 1985; Duara et al., 1987; Moeller et al., 1987), and PET data are therefore often normalized. The sources of this global variability in PET data are not entirely understood, although they very likely include (a) variation in whole brain physiology among individuals, (b) variation in whole brain physiology at different times for the same individual, and (c) errors in the determination of the arterial concentration time course of the radiotracer, which cause nearly uniform biases across the brain. Normalization of data would not affect detection of possible regional differences in uptake (or DV) of ACHC or of alterations in regional uptake patterns following aspartame ingestion. It should be noted that regional differences are detected, with gray matter structures having roughly twice the $K_{1}$ values found for white matter (Koeppe et al., 1990), whereas DV differences between gray and white matter are much smaller. However, substantial aiterations in regional patterns of $\left[{ }^{11} \mathrm{C}\right] \mathrm{ACHC}$ uptake or DV were not detected following aspartame ingestion (Tables 3 and 4). In $\left[{ }^{11} \mathrm{C}\right] \mathrm{ACHC}$ autoradiograms in the marmoset (Washburn et al., 1982), the distribution observed corresponded to that seen for amino acid incorporation into protein, a result suggesting that regional distribution of the LNAA carrier corresponds to synthetic capacity.

Because amino acid transport from blood into scalp does not appear to be dependent on a saturable process in the normal range of plasma amino acid levels, normalizing brain values to that for the scalp was considered to be potentially useful in this test-retest study. Significance levels in test-retest scans using such normalized data (Table 4) were little different than those obtained using absolute data, in spite of the fact that scalp uptake rates did not vary between scans. This may, in part, reflect that different brain regions are more tightly coupled to one another physiologically than are a brain region and a nonbrain region, such as the scalp.

One of the major limitations of the test-retest scan design, as implemented in our study, concerns an inherent assumption of the kinetic model. That is, the model parameters being estimated, namely, $K_{1}$ and DV, must remain constant throughout the time course of the PET measurement. As can be seen in both Fig. 1 and Table 1, plasma phenylalanine levels were not stable during the course of the second PET scan in those subjects who were given aspartame. Therefore, we expect that the parameter we are most interested in measuring does indeed vary during the course of the PET scan. Phenylalanine levels in brain tissue will also vary but with a different temporal course than plasma levels. Thus, we also expect the clearance rate to vary but in a different manner than $K_{1}$. Finally, because the estimate of DV is given by the ratio of $K_{1} /$ $k_{2}$, we also expect it to vary over time as well.

A 45-min postprandial peak of plasma phenylalanine concentration was anticipated (Stegink et al., 1977), thus dictating the time for injection of the second $\left[{ }^{11} \mathrm{C}\right] \mathrm{ACHC}$ dose. It was also anticipated that plasma phenylalanine levels would decline as brain uptake of [ $\left.{ }^{11} \mathrm{C}\right] \mathrm{ACHC}$ progressed. The estimate of $K_{1}$ then becomes a weighted average of the values of the transport rate over the course of the experiment, with the estimate being most strongly influenced by the values shortly after $\left[{ }^{11} \mathrm{C}\right] \mathrm{ACHC}$ injection, at which time the plasma phenylalanine levels were presumably highest. Thus, the $K_{1}$ values reported in this study primarily reflect the transport rate during the peak of competitive inhibition. At times substantially earlier or later, the observed effect should be smaller. This is supported by the fact that subject 7 of the "aspartame" group (Table 2 ), whose scan was started $<20$ min following aspartame ingestion (rather than 40-45 min), exhibited very little change in the estimated transport rate or DV, and the subject whose scan was started $1 \mathrm{~h}$ following aspartame ingestion (subject 2) exhibited moderate declines. The three persons who demonstrated the greatest responses (subjects 3,4 , and 8 ) were all scanned between 35 and 45 min after aspartame ingestion. 
The temporal order of the baseline and aspartame scans could not be reversed conveniently, as would be desirable in a randomized experimental design, because of the finite time required for plasma phenylalanine levels to return to baseline following administration of aspartame. One must, therefore, consider whether the order of the scans might have caused the observed decreases in BBB transport. Results presented in Table 4 offer support that the order of the studies does not explain the observed decreases. Comparison of each subject's first PET scan between "control" and "aspartame" groups (both baseline scans) showed no statistically significant differences (by unpaired Student's $t$ test), whereas comparisons of the retest scans (baseline scans for the "control" group vs. aspartame challenge scans for the "aspartame" group) demonstrated significant differences near the $p<0.05$ level in amino acid transport in all brain regions examined except the cerebellum. Scalp values, as expected, were not significantly different between groups in either the first or second scan.

These experiments demonstrate the suitability of $\left[{ }^{11} \mathrm{C}\right] \mathrm{ACHC}$, a nonmetabolized amino acid analog, for the evaluation of regional uptake of physiologically important amino acids in human brain by means of positron emission techniques. Using large oral doses of aspartame, we were able to demonstrate small but measurable decreases in LNAA uptake. The values for the transport rate constant, $K_{1}$, from $\mathrm{ACHC}$ pre- and post-ingestion of aspartame can be used to calculate the $K_{\mathrm{i}}$ for competing phenylalanine provided that $K_{\mathrm{i}}$ values are known (or assumed) for the other competing amino acids. Using $K_{\mathrm{m}}$ values of the amino acids reported for rats (Aoyagi et al., 1988), a $K_{\mathrm{i}}$ in human for phenylalanine in the range of $50 \mu \mathrm{mol} / \mathrm{L}$ was estimated from subjects in the "aspartame" group. Although a $K_{\mathrm{i}}$ value for phenylalanine theoretically can be calculated for each individual's pair of studies, the minimal nature of the effect of aspartame and the variability encountered discourage making such a calculation. The $K_{\mathrm{m}}$ for phenylalanine reported in the rat was $11 \mu \mathrm{mol} /$ L (Aoyagi et al., 1988), whereas the $K_{\mathrm{m}}$ for the lowaffinity transport system in human brain was reported to be $22.3 \mu \mathrm{mol} / \mathrm{L}$ (Choi and Pardridge, 1986).

The $\left[{ }^{11} \mathrm{C}\right] \mathrm{ACHC}$ technique should prove beneficial for further in vivo human studies, such as the measurement of the kinetic parameters of brain amino acid uptake, as well as DV. For this, a higher level of plasma phenylalanine and thereby of LNAA transport inhibition than is achievable with aspartame is desirable. This can be accomplished by oral administration of phenylalanine itself, rather than aspartame.

Acknowledgment: This work was supported by a grant from the Nutrasweet Company and from National Institutes of Health grant P01-NS15655 awarded by NINCDS. We are grateful to Dr. Seymour Kaufman, Laboratory of Neurochemistry, NIMH, for useful discussions. The authors would like to thank the Nuclear Medicine PET staff for production of radiopharmaceuticals and for acquisition of PET data reported in this work.

\section{REFERENCES}

Alpert N. M., Eriksson L., Chang J. Y., Bergstrom M., Litton J. E., Correia J. A., Bohm C., Ackerman R. H., and Taveras J. M. (1984) Strategy for the measurement of regional cerebral blood flow using short-lived tracers and emission tomography. I. Cereb. Blood Flow Metab. 4, 28-34.

Aoyagi M., Agranoff B. W., Washburn L. C., and Smith Q. R. (1988) Blood-brain barrier of transport aminocyclohexanecarboxylic acid, a nonmetabolizable amino acid for in vivo studies of brain transport. J. Neurochem. 50, 1220-1226.

Butchko H. and Kotsonis F. (1989) Aspartame: review of recent research. Comments Toxicol. 3, 253-278.

Choi T. B. and Pardridge W. M. (1986) Phenylalanine transport at the human blood-brain barrier. J. Biol. Chem. 261, 6536-6541.

Duara R., Gross-Glenn K., Barker W. W., Chang J. Y., Apicella A., Loewenstein A., and Boothe T. (1987) Behavioral activation and the variability of cerebral glucose metabolic measurements. J. Cereb. Blood Flow Metab. 7, 266-271.

Fernstrom J. D., Wurtman R. J., Hammerstrom-Wiklund B., Rand W. M., Numro H. M., and Davidson C. S. (1979) Diurnal variations in plasma concentration of tryptophan, tyrosine, and other neutral amino acids: effect of dietary protein intake. Am. J. Clin. Nutr. 32, 1912-1922.

Food and Drug Administration (1981) Fed. Regist. 46, 38285.

Fox P. T., Mintun M. A., Raichle M. E., and Herscovitch P. (1984) A noninvasive approach to quantitative functional brain mapping with $\mathrm{H}_{2}{ }^{15} \mathrm{O}$ and positron emission tomography. J. Cereb. Blood Flow Melab. 4, 329-333.

Frey K. A. (1989) Positron emission tomography, in Basic Neurochemistry: Molecular, Cellular, and Medical Aspects, 4th ed. (Siegel G. J., Agranoff B. W., Albers R. W., and Molinoff P. B., eds), pp. 839-855. Raven Press, New York.

Hargreaves K. M. and Pardridge W. M. (1988) Neutral amino acid transport at the human blood-brain barrier. J. Biol. Chem. 263, 19392-19397.

Hayes R. L., Washburn L. C., Wieland B. W., Sun T. T., Anon J. B., Butler T. A., and Callahan A. P. (1978) Synthesis and purification of ${ }^{11} \mathrm{C}$-carboxyl-labeled amino acids. Int. J. Appl. Radiat. Isot. 29, 186-187.

Hurwitz A. (1989) Aspartame and sucrose increase the plasma phenylalanine to large neutral amino acid ratio in healthy subjects. FASEB J. 3, A 1251 .

Homler B. E. (1984) Properties and stability of aspartame. Food Technol. 38, 50-55.

Kaufman S. (1977) Phenylketonuria: biochemical mechanisms, in Advances in Neurochemistry, Vol. 2 (Agranoff B. W. and Aprison M. H., eds), pp. 1-133. Plenum Press, New York.

Koeppe R. A., Mangner T., Betz A. L., Shulkin B. L., Allen R., Kollros P., Kuhl D. E., and Agranoff B. W. (1990) Use of ${ }^{11}$ Caminocyclohexanecarboxylate for the measurement of amino acid uptake and distribution volume in human brain. J. Cereb. Blood Flow Metab. 10, 727-739.

Lee P. L. Y. (1974) Single column system for accelerated amino acid analysis of physiological fluids using five lithium buffers. Biochem. Med. 10, 107-121.

Martin-Du Pan F., Mauron C., Glaeser B., and Wurtman R. J. (1982) Effect of various oral glucose doses on plasma neutral amino acid levels. Metabolism 31, 937-943.

Mazziotta J. C., Huang S.-C., Phelps M. E., Carson R. E., MacDonald N. S., and Mahoney K. (1985) A noninvasive positron computed tomography technique using oxygen-15-labeled water for the evaluation of neurobehavioral task batteries. J. Cereb. Blood Flow Metab. 5, 70-78.

Moeller J. R., Strother S. C., Siditis J. J., and Rottenberg D. A. (1987) Scaled subprofile model: a statistical approach to the analysis of functional patterns in positron emission tomographic data. $J$. Cereb. Blood Flow Metab. 7, 649-658. 
Mondino A., Bongiovanni G., and Fumero S. (1975) A new approach for obtaining total tryptophan recovery in plasma samples deproteinized with sulphosalicylic acid. J. Chromatogr. 104, 297302.

Oldendorf W. H. (1970) Measurement of brain uptake of radiolabeled substances using a tritiated water internal standard. Brain Res. 24, 372-376.

Oldendorf W. H. and Braun L. D. (1976) Tryptamine and ${ }^{3} \mathrm{H}$-water as diffusible internal standards for measuring brain extraction of radio-labeled substances following carotid injection. Brain Res. 113, 219-224.

Pardridge W. M. (1977) Kinetics of competitive inhibition of neutral amino acid transport across the blood brain barrier. J. Neurochem. 28, 103-108.

Pardridge W. M. (1983) Brain metabolism: a perspective for the blood brain barrier. Physiol. Rev. 63, 1481-1535.

Pardridge W. M. (1986) Mechanisms of neuropeptide interaction with the blood brain barrier. Ann. NY Acad. Sci. 481, 231-249.

Rampini S., Anders P. W., Courtis H. C., and Marthaler T. (1969)
Detection of heterozygote for phenylketonuria by column chromatography and discriminatory analysis. Pediatr. Res, 3, 287297.

Smith Q. R., Momma S., Aoyagi M., and Rapoport S. I. (1987) Kinetics of neutral amino acid transport across the blood-brain barrier. $J$. Neurochem. 49, 1651-1658.

Stegink L. D., Fyler L. J. Jr., and Baker G. L. (1977) Effect of aspartame and aspartate loading upon plasma and erythrocyte free amino acid levels in normal adult volunteers. $J$. Nutr. 107, $1837-1845$.

Washburn L. C., Ringenberg R. E., Sun T. T., and Hayes R. L. (1981) " $\mathrm{C}$-Labeled 1-aminocyclohexanecarboxylic acid (" $\mathrm{C}$ ACHC), a potential agent for studies of amino acid transport in the brain. J. Label. Comp. Radiopharm. 18, 13-14.

Washburn L. C., Sun T. T., Byrd B. L., Rafter J. J., Hayes R. L., Frey K. A., and Agranoff B. W. (1982) ${ }^{11} \mathrm{C}-\mathrm{ACHC}$, a potential agent for positron tomographic measurement of brain amino acid transport, in Nuclear Medicine and Biology, Vol. I (Raynaud C., ed), pp. 642-645. Pergamon Press, Paris. 